\title{
Rapid Sprouting of Filopodia in Nerve Terminals of Chromaffin Cells, PC12 Cells, and Dorsal Root Neurons Induced by Electrical Stimulation
}

\author{
Shanthi Manivannan and Susumu Terakawa \\ Department of Cell Physiology, National Institute for Physiological Sciences, Myodaiji, Okazaki 444, Japan
}

Rapid morphological changes induced by direct electrical stimulation of nerve terminals were studied by using videoenhanced differential interference contrast microscopy at a very high magnification $(12,000 \times)$. We used mainly cultured bovine chromaffin cells, which developed neurite-like processes, and PC12 cells, which showed neuronal differentlation upon NGF treatment. In a few cases, primary neurons of the rat dorsal root ganglion were also examined. Brief pulse stimulation of the terminals and varicosities induced exocytosis accompanied by rapid formation of filopodia. These filopodia, 0.1-0.2 $\mu \mathrm{m}$ in diameter and up to $10 \mu \mathrm{m}$ in length, formed within a few hundreds of milliseconds and then retracted within tens of seconds. They could also be induced by $\mathbf{K}$ depolarization. This rapid filopodial sprouting strongly depended on the presence of extracellular $\mathrm{Ca}^{2+}$ and could be abolished in a medium containing a Ca chelator (EGTA) or $\mathrm{La}^{3+}$. Anti-cytoskeletal agents colchicine and cytochalasin B failed to block this response completely but lidocaine fully suppressed it. Quantitative analysis of exocytosis and filopodial sprouting showed that they were independent events, not directly linked to each other, having different threshoids usually higher for filopodial formation. In PC12 cells, the extent of filopodial sprouting varied with the state of differentiation of the cells, suggesting a functional role of rapid sprouting during a particular phase of their differentiation. Filopodia could be induced with greater ease by repetitive stimulation. The same responses may occur at growth cones approaching the target cells or even at mature synapses particularly after repetitive electrical activity, possibly playing a role in use-dependent synapse formation or plasticity.

[Key words: chromaffin cell, sprouting, growth cone, filopodium, exocytosis, lidocaine]

\footnotetext{
Received June 7, 1993; revised Mar. 15, 1994; accepted Mar. 24, 1994.

Wc thank Dr. K. Kumakura for providing dissociated chromaffin cells, Dr. K. Yamaguchi for providing dorsal root ganglion neurons, Ms. R. Sakurai and Ms. A. Miwa for maintaining the chromaffin cells in culture, Mr. M. Ohara for electronical assistance, and Messrs. A. Ito, F. Mizutani, and M. Mori for programming the digital photographic printer. S.M. was supported by a fellowship from Uehara Memorial Life Science Foundation. This work was partly supported by a grantin-aid (01480118) from The Ministry of Education, Science and Culture, Japan to S.T.

Correspondence should be addressed to Susumu Terakawa, Photon Medical Research Center, Hamamatsu University School of Medicine, 3600 Handa, Hamamatsu, 431-31, Japan.

Copyright (C) 1994 Society for Neuroscience $0270-6474 / 94 / 145917-12 \$ 05.00 / 0$
}

Electrical activity plays a prominent role in communications within the nervous system. It has been suggested that electrical activity might influence the morphological characteristics and functional connectivity in the nervous system during development and in neuroplastic events. In fact, electrical activity influences various neuronal properties like synthesis of neurotransmitters (Walicke et al., 1977; Ip and Zigmond, 1984), expression of neurotransmitter receptors (Lomo and Rosenthal, 1972; Zigmond and Bowers, 1981), the rate and direction of neurite outgrowth (Borgens et al., 1981; Patel and Poo, 1982; Cohan and Kater, 1986), formation and pattern of synaptic connections (Changeux and Danchin, 1976; Archer et al., 1982), and sprouting at the neuromuscular junction (Brown and Ironton, 1977; Brown et al., 1981). Receptor-mediated changes in the morphology and the activity of the ncuronal growth conc have been shown to be induced by serotonin (Haydon et al., 1984) and nerve growth factor (NGF) (Connolly et al., 1987). Glutamate, an excitatory neurotransmitter, induces filopodia formation in the growth cone (Cornell-Bell et al., 1990). Application of an electrical field or a K-rich solution increases the number, facilitates elongation, and induces disposition of filopodia (Davenport and Kater, 1992; Rehder and Kater, 1992). Thus, motility and structural changes of the growth cone have been extensively studied. However, very little is known about the immediate or rapid morphological changes of the growth cone resulting from electrical activities as brief as the action potential. Since brief action potentials are usual under physiological conditions in vivo, effects of such electrical activities, if any, on growth cones would be important for their steering toward targets or for their transformation into synaptic terminals.

In this study, we employed bovine chromaffin cells and a pheochromocytoma cell line PC12 cultured in a low density as a model neuron, and observed the terminal of neurites under a video-enhanced differential interference contrast microscope at a very high magnification $(12,000 \times)$. An electrical pulse of 1 msec duration was used to stimulate the terminal to mimic or actually induce such an action potential as those normally generated under physiological conditions. We found a rapid sprouting of filopodia in nerve terminals immediately after this brief electrical stimulation. In order to gain some insights into the activities of filopodia, their rapid sprouting was studied with special emphases on its ionic and chemical sensitivities and on its relationship with exocytosis occurring at the same terminal. Here, we describe the basic properties of this unusual response, and present evidence for its biological significance. 

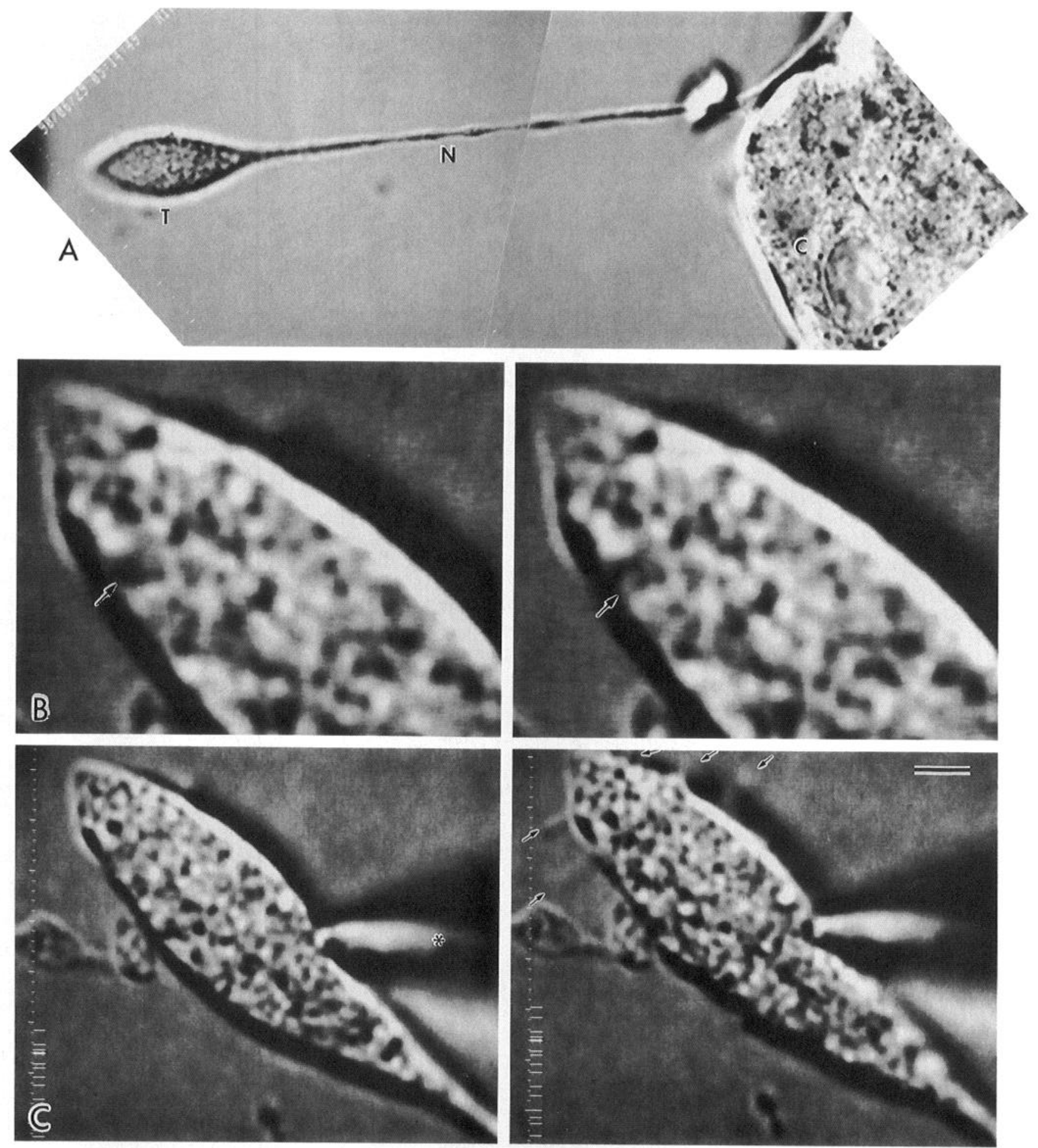

Figure 1. Exocytosis of a granule and sprouting of filopodia in a terminal of a chromaffin cell neurite. $A$, Low-magnification Nomarski image of differentiated chromaffin cells in culture. Several cells $(C)$ with nuclei and a neurite $(N)$ with a swollen terminal $(T)$ are shown. $B$, Series of highmagnification images of the terminal in $A$ taken $1 \mathrm{sec}$ after electrical stimulation $(1.40 \mu \mathrm{A}, 1 \mathrm{msec})$. A granule (arrow, left) abruptly changed in brightness and in shape, giving an impression of popping (arrow, right; taken at a $66 \mathrm{msec}$ interval). More than 50 of such responses continued to appear in $5 \mathrm{sec}$. $C$, Images of the same terminal immediately before (left) and $8 \mathrm{sec}$ after (right) stimulation with a current pulse of a slightly larger amplitude $(1.54 \mu \mathrm{A})$. Several filopodia sprouted rapidly (arrows). Asterisk, micropipette. The images were recorded as described in Materials and Methods. Scale bars in $C: A, 5 \mu \mathrm{m} ; B, 1 \mu \mathrm{m} ; C, 2 \mu \mathrm{m}$.

Preliminary results were reported in the 3rd IBRO World Congress of Neuroscience, Montreal, 1991, and in the 17 th Seiriken Conference, Okazaki, 1992 (see Manivannan and Terakawa, 1993).

\section{Materials and Methods}

Cell culture. Chromaffin cells were isolated from bovine adrenal medullae by the collagenase digestion method (Waymire et al., 1983). The cells were differentially plated and cultured on collagen-coated cover- 

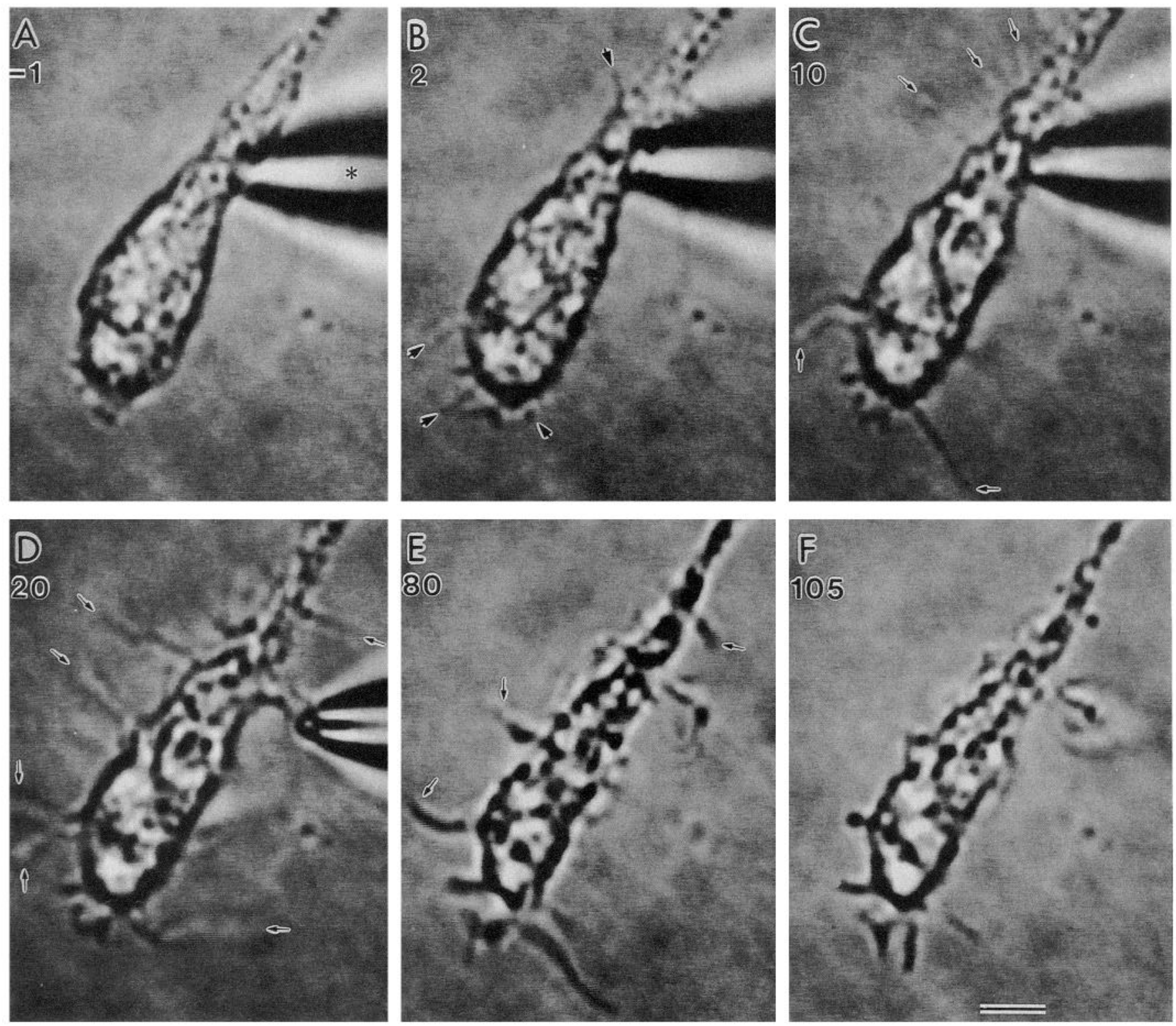

Figure 2. A sequence of filopodial sprouting and retraction in a terminal of a chromaffin cell neurite. Images were taken before $(A)$ and at various times after (indicated in seconds, $B-F$ ) after electrical stimulation. Several filopodia started to sprout in a fraction of second (arrows in $B$ ) and fluctuated off focus (arrows in $C$ and $D$ ). Conspicuous raster lines (arrows in $E$ ) are due to the rapid movement of filopodia during the interlace scan. Asterisk, micropipette. Scale bar, $2 \mu \mathrm{m}$.

slips in Dulbecco's modified Eagle's medium (DMEM) supplemented with $10 \%$ fetal calf serum (FCS). PC12 cells (subclone $\mathrm{PC} 12 \mathrm{~h}$ having an NGF-sensitive tyrosine hydroxylase activity; Hatanaka, 1981) were also cultured on collagen-coated coverslips in DMEM supplemented with $5 \%$ FCS. The latter cells were further treated with nerve growth factor (NGF; $50 \mathrm{ng} / \mathrm{ml}$; Sigma, St. Louis, MO) from the second day of culture onward and were studied after various periods of NGF treatment. Primary neurons were dissociated from the dorsal root ganglion of adult rats by the collagenase digestion method. They were cultured on a polylysine-coated coverslip in a serum-free N1 medium for $3 \mathrm{~d}$ (for details, see Yamaguchi, 1990).

Video microscopy. The cells were examined under an inverted Nomarski microscope equipped with a $100 \times$ DIC objective lens and a $2.5 \times$ insertion lens (Axiovert 35, Zeiss). The coverslip plated with the cultured cells was fixed with petroleum jelly (Vaseline) to a square hole made in the center of a plastic slide. The slide was placed on the microscope stage warmed with an electric heater. Using a peristaltic pump (SJ-1220, Atto, Tokyo), the cells were perfused continuously with warmed and oxygenated solution. The temperature of the perfusion chamber was maintained at $32-36^{\circ} \mathrm{C}$. The optical image was detected with a 0.5 inch CCD video camera (TI-23P, NEC, Tokyo), and the contrast of the image was enhanced with a high-speed digital image processor (PIP4000 , ADS, Osaka). The processed image was observed on a slightly overscanned video monitor (14 inches, B/W, Hitachi, Tokyo), and simultaneously videotaped with an S-VHS format recorder (AG-7750, Panasonic, Osaka). The ratio of the effective scanning width of the monitor to that of the CCD detector reached 48 , and thus increased the total magnification to $12,000 \times$. Pictures were reproduced by digitizing necessary video frames and printing with a digital photographic printer (Pictrography 2000, Fujix, Tokyo).

Stimulation. Neurite terminals and varicosities were stimulated directly with an electrical pulse from a glass micropipette placed extracellularly. The micropipette was $0.5-1.5 \mu \mathrm{m}$ in diameter, filled with the normal solution (see below) and connected to a piece of $\mathrm{Ag}-\mathrm{AgCl}$ wire. It was held by a water-driven micromanipulator (WR-3, Narishige, Tokyo). The tip of the micropipette was pressed gently to the surface of the terminal or varicosity. The ground electrode was a coil of $\mathrm{Ag}$ $\mathrm{AgCl}$ wire immersed in a corner of the chamber. Currents were passed 

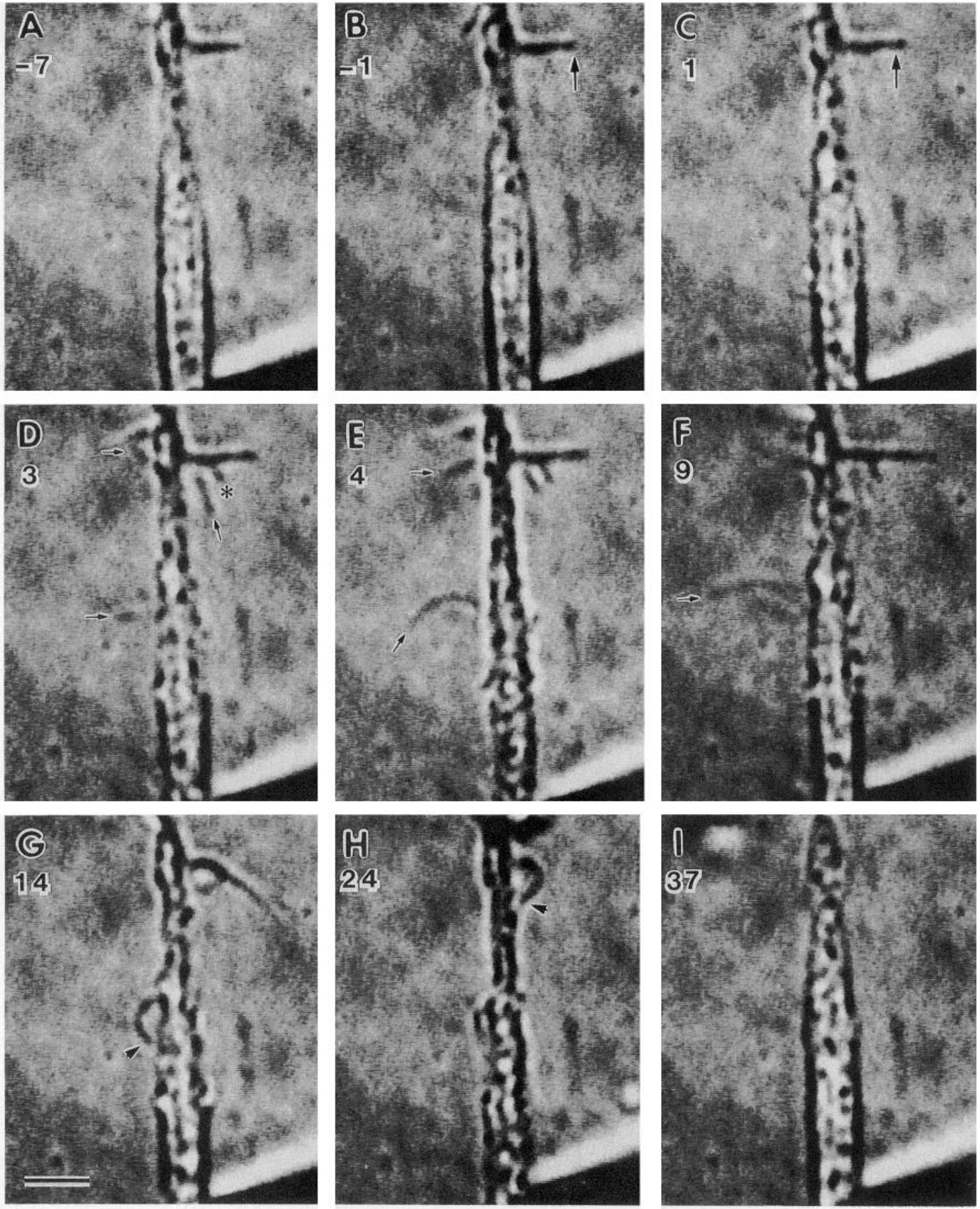

Figure 3. Elongation of a stable filopodium (large arrows) and sprouting of filopodia (small arrows) followed by retraction by falling back in a chromaffin cell terminal. This terminal was comparatively thin, but still possessed common terminal characteristics such as a swollen body, accumulated granules, and a tapered tip (located on the top side). Sequential images were taken before $(A$ and $B)$ and at various times after (indicated in seconds, $C-I$ ) stimulation. The stable filopodium elongated and developed a branch (asterisk) upon electrical stimulation (large arrows were placed at the same position in $B$ and $C$ ). Subsequently, retraction of filopodia occurred by bending and falling back on the neurite (arrowheads). Scale bar, $2 \mu \mathrm{m}$.

from the pipette to the ground electrode so that a major part of the terminal or varicosity membrane was depolarized upon stimulation. A single stimulus was a current pulse of $1-2 \mu \mathrm{A}$ in amplitude and $1 \mathrm{msec}$ in duration. In the case of repetitive stimulation, four pulses of the same strength were given at an interval of $300 \mathrm{msec}$ in a train. The amplitude of the pulse was fed to the image processor, displayed on the video monitor, and recorded in the videotape in superposition with the microscopic image. Depolarizing stimulation was also given by applying a solution containing a high concentration of $\mathrm{KCl}$ to the terminal or varicosity from a glass micropipette (tip diameter, 4-5 $\mu \mathrm{m}$ ), placed at a distance of $5 \mu \mathrm{m}$ from the terminal. Electromagnetic valves were used to control the outlet flow of the solution from the pipette. The K-rich solution was prepared by substituting $65 \mathrm{mM} \mathrm{KCl}$ for $\mathrm{NaCl}$ in the normal solution (see below).

Solutions. The normal solution (NS) contained (in mм) $\mathrm{NaCl}, 132$; $\mathrm{KCl}, 5 ; \mathrm{CaCl}_{2}, 2 ; \mathrm{MgCl}_{2}, 2 ;$ glucose, 5-10; HEPES, 10 (pH adjusted to 

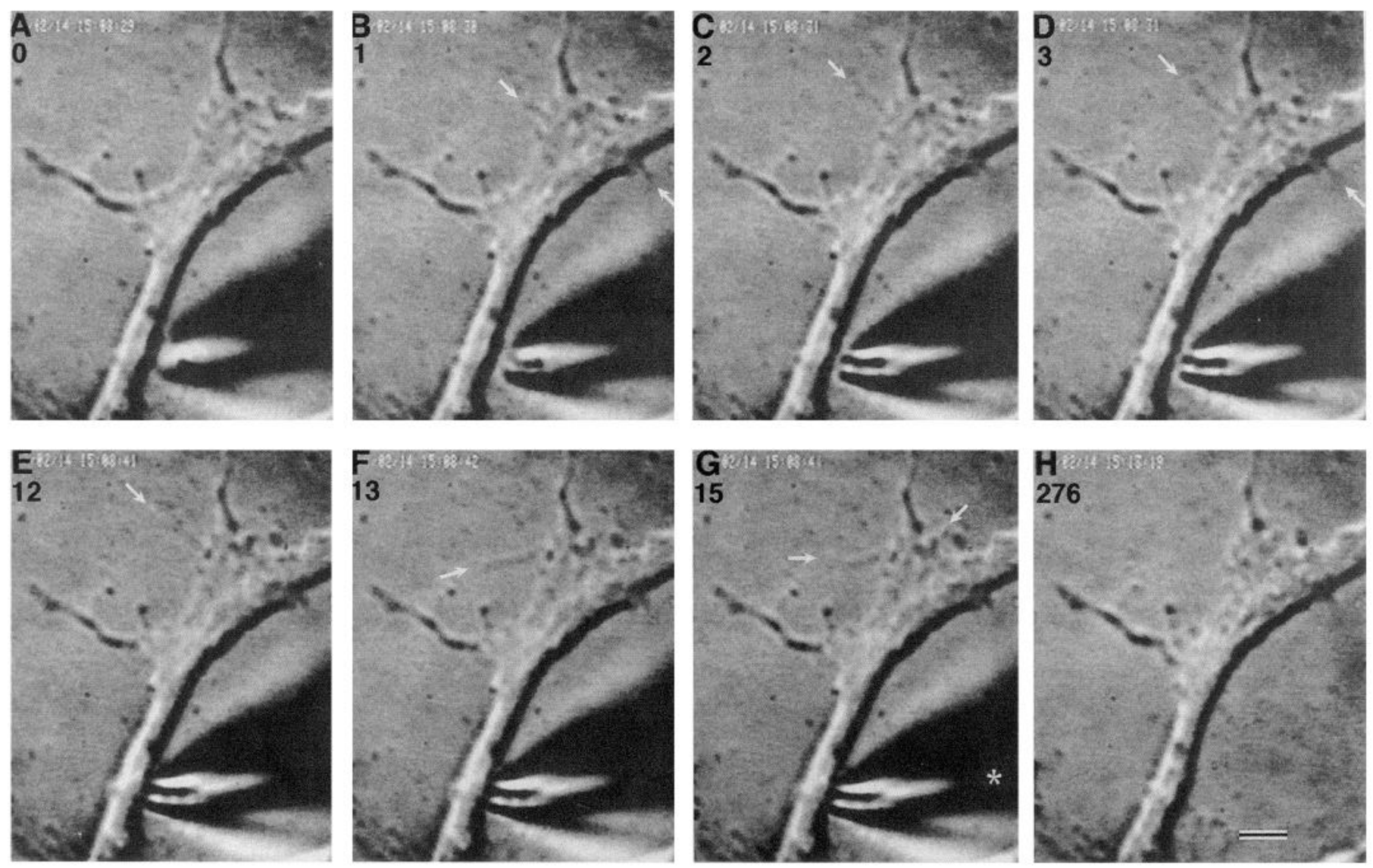

Figure 4. Rapid sprouting of filopodia in a growth cone of the rat dorsal root neuron. $A$, Video frame showing a growth cone possessing several filopodia of a stable type. The frame was taken immediately before electrical stimulation. $B-G$, Video frames taken consecutively after electrical stimulation with a single pulse $(\sim 1.7 \mu \mathrm{A})$. Three thin filopodia (arrows) appeared and elongated for a while. The blurred image of these filopodia was due to their rapid fluctuation. $H$, Video frame taken after complete retraction of the sprouted filopodia. Note that filopodia observed before stimulation remained unaltered. The number in each frame indicates time (in seconds) relative to the onset of electrical stimulation. Asterisk, micropipette. Scale bar, $2 \mu \mathrm{m}$.

7.4 with $\mathrm{NaOH})$. For $\mathrm{Ca}^{2+}$-free experiments, $\mathrm{CaCl}_{2}$ was either omitted from NS or replaced with $2 \mathrm{~mm}$ ethyleneglycol-bis(2-aminoethylether)tetraacetate (EGTA). When necessary, $\mathrm{LaCl}_{3}$, lidocaine, verapamil, or nifedipine was added to NS. Colchicine was dissolved in NS and added to the culture medium directly. The cells were studied 3-5 hr after treatment with colchicine. Cytochalasin B was first dissolved in a small quantity of dimethyl sulfoxide (DMSO), and then this solution was added to NS. The final concentration of DMSO was kept below $0.5 \%$. All concentrations mentioned were final concentrations in the medium.

\section{Results}

\section{Formation and retraction of filopodia}

Bovine chromaffin cells developed neurite-like processes after a few days in culture. PC12 cells cultured in a medium supplemented with NGF also differentiated into neuronal cells, and developed long neurites in a few days. These neurites in both types of cells grew to $300 \mu \mathrm{m}$ in length and occasionally formed synapse-like contacts with neighboring cells. A single cell produced one to six neurites. The growing ends of neurites sometimes showed characteristics typical to the growth cone, having lamellipodia and microspikes or filopodia, but quite often appeared as round swellings with smooth tips (Fig. 1A). Some of the neurites had varicosities along their course. The terminals and varicosities were rich in small secretory granules. Upon electrical stimulation of a neurite terminal or varicosity, exocytosis occurred in the form of an abrupt change in light intensity of the granules as described previously (Terakawa et al., 1991, 1992, 1993a,b; details will be published elsewhere) (Fig. 1B). In addition to exocytosis, when the same terminal was stimulated with a slightly larger pulse, thin thread-like structures resembling filopodia or microspikes were formed rapidly from the round and smooth part of the varicosity and the terminal (Figs. $1 C, 2)$. Hereafter, we will refer to them as filopodia. Rapid sprouting of filopodia, as many as 15 in number from a single terminal or varicosity occurred after a latency of less than 100 msec. They reached their maximal length at variable times (1$10 \mathrm{sec}$ ). The maximal length was also variable, ranging from 1 to $10 \mu \mathrm{m}$. The filopodia were $0.1-0.2 \mu \mathrm{m}$ in apparent diameter. They appeared to be very flexible and were constantly fluctuating in Brownian movement. It was difficult to obtain a clear photographic image of them, because of this fluctuation. However, when observed on a video in real time, these responses could be figured out with ease and clarity. Some of the terminals developed rigid and stable filopodia during culture. This classical type of filopodia did not show Brownian movement. Some of these stable filopodia also grew rapidly in length or sprouted branches immediately after electrical stimulation (Fig. 3).

Formation of filopodia was followed soon after by their retraction. The retraction was either complete or partial to leave short stable filopodia. In most cases, filopodia retracted as rapidly as they formed, but occasionally it took longer for them to 

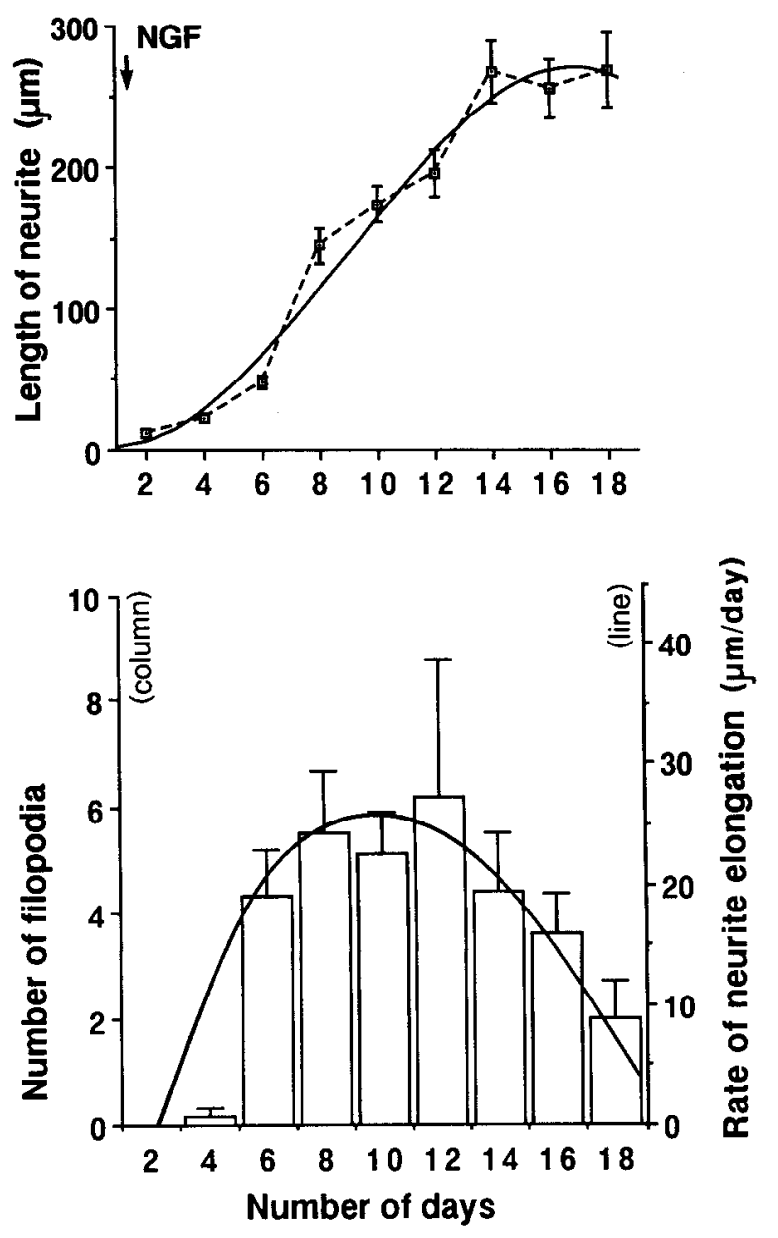

Figure 5. Growth curve of the neurite (top), and correlation of the ability to sprout filopodia rapidly (bottom, columns) with the rate of neurite elongation (bottom, solid line) in PC.12 cells. The cells, treated with NGF, were examined for filopodial sprouting upon electrical stimulation on different days of culture. Top. The length of a neurite was determined by adding lengths of several straight segments of that neurite. Data for each point were obtained from 60 neurites randomly chosen from many cells cultured in two dishes continuously for 3 weeks. The solid line is a regression curve made using a third-order polynomial function. Bottom, The rate of neurite elongation $(R)$ was calculated from the mean length of neurites shown at top and presented against the number of days $(D)$ after curve fitting using a third-order polynomial function: $R=0.01880 D^{3}-0.960 D^{2}+12.85 D-25.8$. The filopodial sprouting ability was measured from the number of filopodia that were induced in a single terminal ( 13 different terminals were examined for each time point). Error bars indicate the SEM. The abscissae represent the number of days after NGF introduction (arrow).

retract completcly. The filopodia usually retracted by shortening their length, but in some cases, long filopodia retracted by bending and falling back on the mother neurite (Fig. 3). In this case, the tip of the filopodium attached to the neurite surface first, and then the rest of the filopodium temporarily formed an arch. Soon, the arch fell on the terminal and apparently fused with it.

Filopodial sprouting followed by retraction could be repeatedly induced from the same terminal or varicosity for five to eight times, if the interval between stimuli was more than 1-3 min. Occasionally, the terminal itself swelled by $10-20 \%$ immediately after electrical stimulation and later shrank back in a time course similar to retraction of filopodia (Fig. 2). The extent of swelling seemed to be larger when the terminal showed a slower sprouting of filopodia. A very similar sprouting and retraction of filopodia was observed in primary neurons dissociated from the dorsal root ganglion of the rat and cultured in a serum-free medium for $3 \mathrm{~d}$ (Fig. 4), although the rate of occurrence was lower when compared with chromaffin cells.

In order to establish that depolarization of the terminal membrane and not an electrokinetic effect of the stimulating current itself causes filopodial sprouting, we examined the effects of depolarization of the terminal membrane by raising the extracellular $\mathrm{K}^{+}$concentration. Such sustained depolarization usually takes place under a pathological condition in vivo. When the terminals were stimulated by applying a $65 \mathrm{~mm} \mathrm{~K} \mathrm{~K}^{+}$-containing solution from a micropipette, filopodia were formed in a similar manner to those induced by electrical stimulation. The onset of filopodial sprouting was a little slower, but other features of the filopodia with reference to the rate of elongation and retraction, their size and flexibility, and their fate of withdrawal were similar to those of the filopodia induced by electrical stimulation. The exocytotic responses of secretory granules were also induced by K-depolarization in chromaffin cells.

The properties of the growth cone have been shown to vary with age or the state of differentiation of the neuron. We examined if there was any correlation between the filopodia-forming capability and the number of days in culture. We observed that such a correlation did exist in PC12 cells differentiated by NGF treatment. In PC12 cells, the terminals of neurites did not show filopodial sprouting upon electrical stimulation during the first $2 \mathrm{~d}$ after culture was begun. The number of filopodia sprouted in the terminal gradually increased after the second day, and the percentage of electrically stimulated terminals that sprouted filopodia also increased to reach a peak at about 7-8 d after the introduction of NGF to the culture medium. At that age, almost all terminals (close to 95\%) showed filopodial sprouting upon electrical stimulation, and six filopodia on the average were formed in each terminal. We compared the ability to form filopodia (measured by the number of filopodia sprouted in a terminal) with the mean length of neurites in individual terminals (Fig. 5). There seemed to be a close correlation between the neurite elongation phase and the filopodia sprouting capability. When the rate of neurite elongation decreased to a low level after 2 weeks of culture, the capability of terminals to sprout filopodia also decreased.

\section{Repetitive stimulation}

The summative and facilitatory effect of repetitive stimulation is known to occur in terminal responses like the synaptic transmission. To examine whether a similar property is underlying the rapid sprouting of filopodia, we compared the effect of repetitive stimulation on the terminals with that of single pulse stimulation and examined if this could induce filopodial sprouting with greater ease. When a single stimulus of an intensity lower than usual was given to the terminal, only exocytosis occurred and no filopodium formed. When the same terminal was stimulated repetitively four times at an interval of 100-500 msec each with the same stimulus intensity, many filopodia could be induced (Fig. 6). The same was the case in many terminals. Filopodia could not be induced to form when stimulation was given repetitively at intervals longer than $1 \mathrm{sec}$, though exocytotic responses were greatly enhanced. In such cases, filopodial sprouting occurred only when the stimulus intensity was slightly increased. Increasing the number of stimuli in the train over five did not have any additional enhancing effect. 

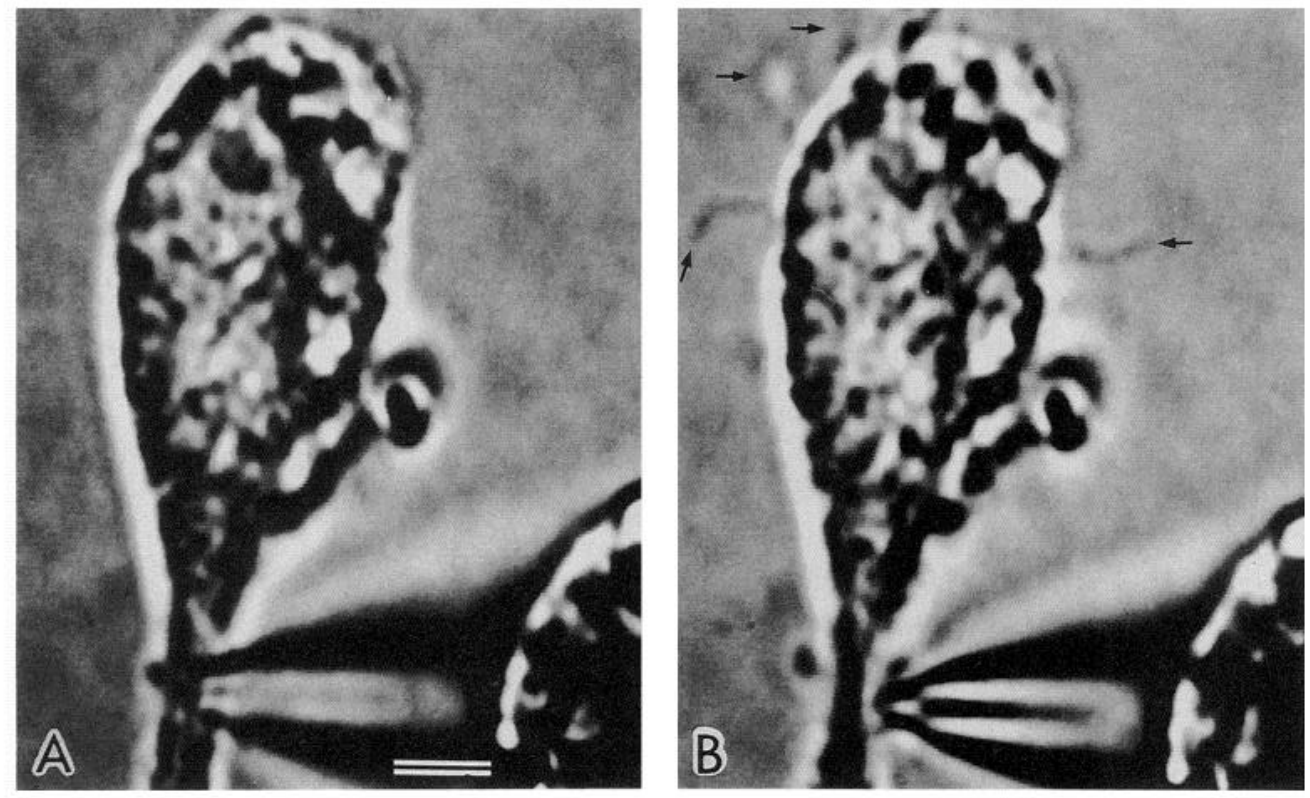

Figure 6. Facilitation of filopodial sprouting by repetitive stimulation. $A$, A chromaffin cell terminal stimulated with a single electrical pulse of $1 \mathrm{msec}$ duration. No filopodium but exocytosis was induced. $B$, The same terminal stimulated with four repetitive stimuli (1 msec duration and $100 \mathrm{msec}$ interval) of the same intensity as used in $A$. Several filopodia (arrows) formed in 5 sec after this repetitive stimulation. Scale bar, $2 \mu \mathrm{m}$.

\section{Calcium dependence of filopodial sprouting}

The rapid formation of filopodia described above depended highly on the presence of $\mathrm{Ca}^{2+}$ in the perfusion medium (Fig. 7). Chromaffin cells that developed long neurites were perfused with NS containing $2 \mathrm{mM} \mathrm{CaCl}_{2}$. In the presence of $\mathrm{Ca}^{2+}$, most of the terminals of these neurites showed filopodial formation upon electrical stimulation. After switching the perfusion solution to the Ca-free medium (no EGTA was used), the response was significantly suppressed within 10-15 min. The average number of filopodia produced by each terminal was decreased to one-fifth the normal ( $p<0.01$, Wilcoxon signed-rank test). When $\mathrm{Ca}^{2+}$ in the perfusion solution was chelated by addition of 2 mM EGTA, filopodial sprouting was totally suppressed ( $p$ $<0.01$ ). In PC1 2 cells, calcium dependence of filopodial sprouting was examined as in chromaffin cells. They also showed a significant decrease in filopodial sprouting when perfused with nominally Ca-free solution $(p<0.01)$. In the presence of $2 \mathrm{mM}$ EGTA, filopodial sprouting was completely suppressed $(p<$ 0.01 ), which was similar to our observation in chromaffin cells. The filopodia sprouting activity showed a significant, if not complete, recovery when perfusion solution was switched back to NS. Effects of lanthanum, a nonspecific Ca-channel blocker, on the rapid filopodial formation were also examined in $\mathrm{PC} 12$ cells. PC12 cells were perfused with NS containing $2 \mathrm{mM} \mathrm{CaCl}_{2}$, to which $0.1 \mathrm{mM} \mathrm{LaCl}_{3}$ was added. Within $10 \mathrm{~min}$ of the beginning of perfusion, the filopodial sprouting was totally and irreversibly suppressed $(p<0.01)$. Selective Ca-channel blocking agents like nifedipine ( $50 \mu \mathrm{M}$ in NS) and verapamil (50 $\mu \mathrm{M}$ in NS) seemed to suppress the response slightly but never completely. These observations suggest that the rapid filopodial sprouting depends primarily on calcium entering through several classes of $\mathrm{Ca}$ channels.

\section{Effect of pharmacological agents}

The filopodia that were normally present on the growth cone during culture appeared to be relatively rigid and not as flexible as the ones that were induced rapidly in response to electrical stimulation. It is known that microfilaments play a role of cy- toskeleton in such rigid filopodia (Forscher and Smith, 1988; Smith, 1988). To examine the involvement of cytoskeletal filaments in the rapid formation of filopodia, chromaffin cells were treated with $5 \mu \mathrm{M}$ colchicine for about $5 \mathrm{hr}$ during culture prior to electrical stimulation or with $5 \mu \mathrm{M}$ cytochalasin B for $15 \mathrm{~min}$

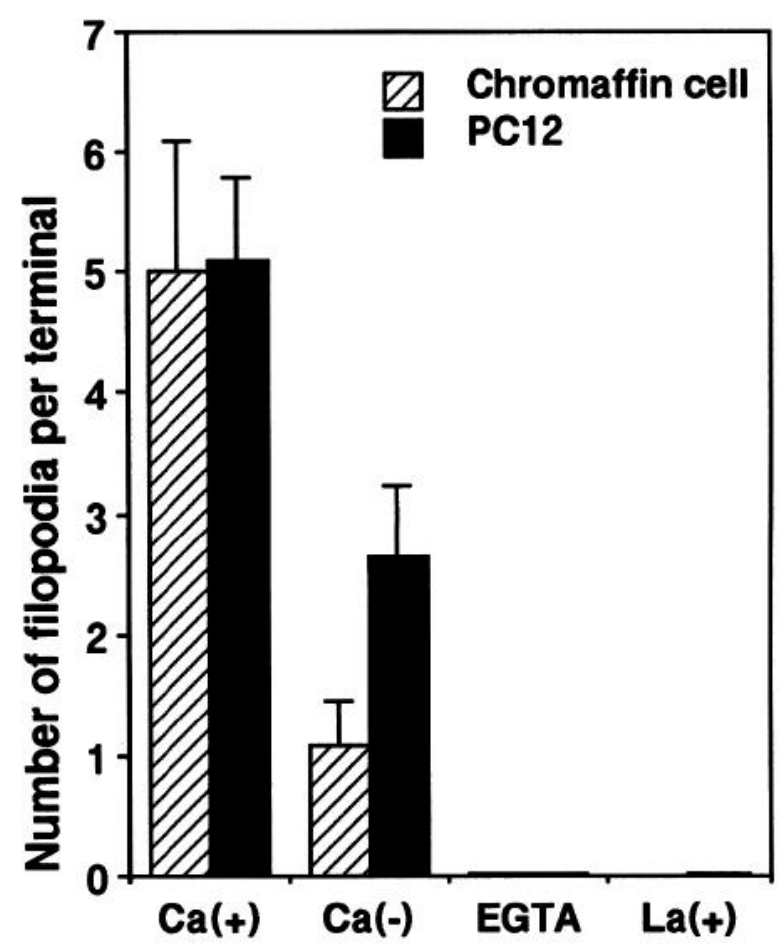

Figure 7. Calcium dependence of filopodial formation in adrenal chromaffin cells (hatched column) and PC12 cells (solid column) cultured for 7-14 d. The cells were perfused with NS $[\mathrm{Ca}(+)]$, NS containing no $\mathrm{Ca}^{2+}[\mathrm{Ca}(-)]$, NS containing no $\mathrm{Ca}^{2+}$, but 2 mM EGTA $(E G T A)$, or NS containing $0.1 \mathrm{mM} \mathrm{LaCl}_{3}[\mathrm{La}(+)]$. The height of the column represents the average number of filopodia induced by the first electrical stimulus applied on each terminal [ 23 different terminals were examined for $\mathrm{Ca}(+)$, and 14 terminals for the rest]. Error bars indicate the SEM. The effect of $\mathrm{La}^{3+}$ was examined in PC12 only. 

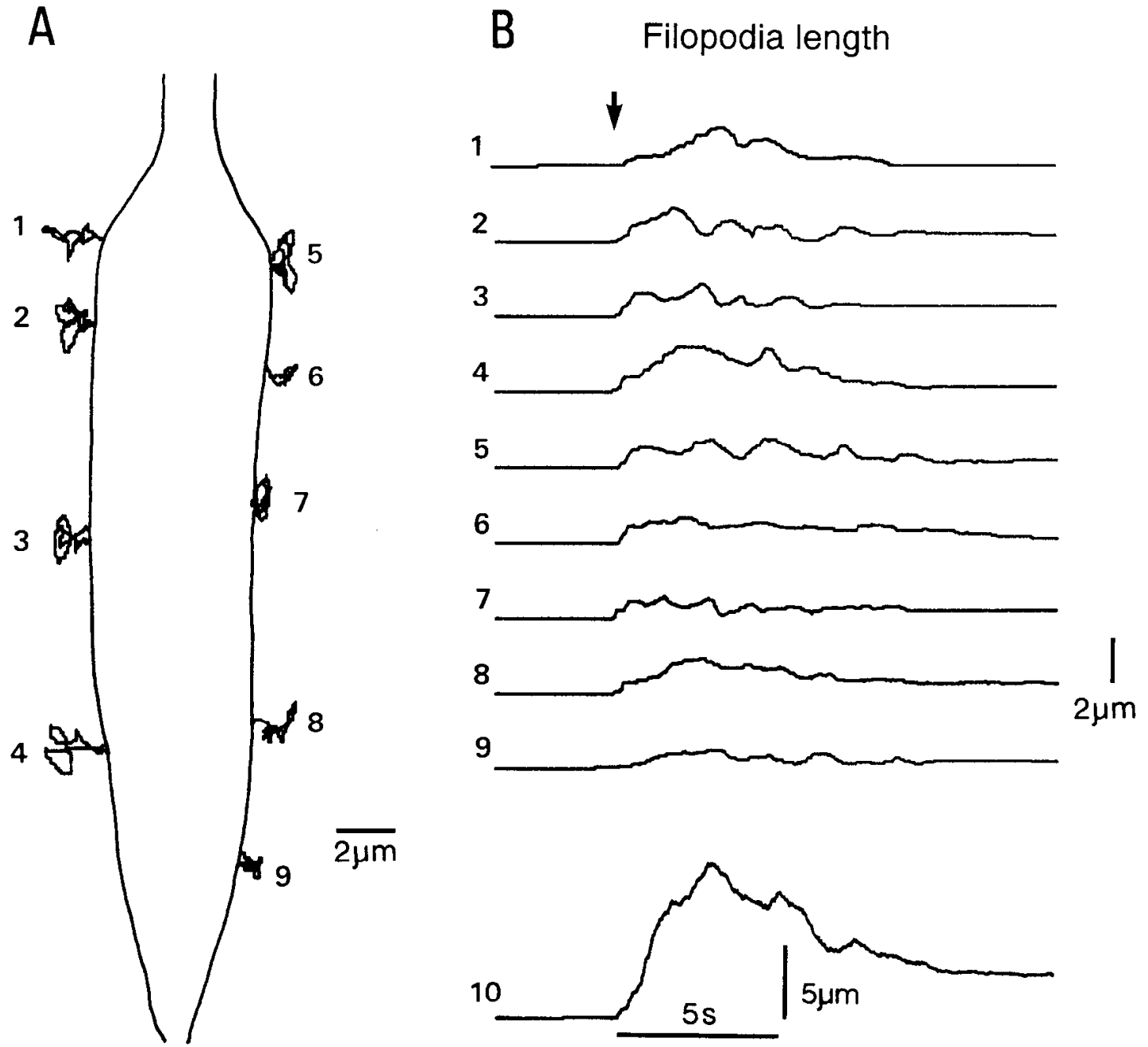
$2 \mu \mathrm{m}$

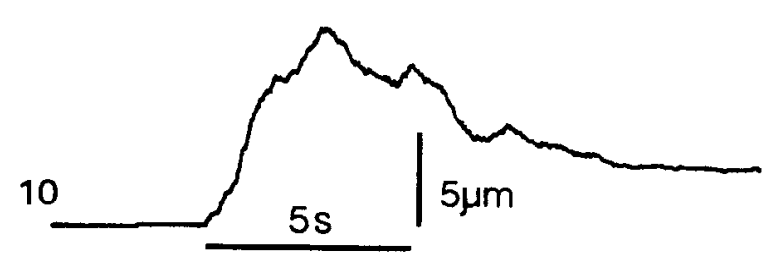

Figure 8. Analysis of filopodial growth and movement. A, Tracings of the movement of the tip of the filopodia in a terminal of a chromaffin cell. This terminal formed nine filopodia (1-9) upon electrical stimulation applied through a micropipette attached to a point between filopodia 7 and 8 . $B$, Each trace indicates the shortest distance of the tip of the filopodia from its source point on the terminal. Trace 1 in $B$ is for filopodia 1 in $A$ and so on. The lowermost trace (trace 10) is the sum of all the above traces. The upward deflection in this particular trace indicates a total of approximate lengths of all filopodia produced by the terminal at each point of time. A stimulus was applied at the time indicated by an arrow. Filopodia that appeared completely off the focal plane were not analyzed.

before electrical stimulation. Both of them failed to block filopodial formation completely, but brought about a small decrease in the number of responding terminals and varicosities. In control, $68 \%$ of the terminals and varicosities $(n=98)$ showed filopodial sprouting. In comparison to this, $66 \%$ of the terminals and varicosities examined after colchicine treatment $(n=9)$ and $55 \%$ of those stimulated after cytochalasin B treatment $(n=9)$ continued to show filopodial sprouting. The mean number of filopodia induccd in a singlc terminal was decreased slightly, but the statistical significance for this was not sufficiently high. The number of filopodia per terminal was $5.09 \pm 1.06$ (mean \pm SEM) in control, $4.44 \pm 1.61$ after colchicine treatment, and $4.33 \pm 1.86$ after cytochalasin B treatment.

One agent that blocked filopodial formation efficiently was lidocaine. Lidocaine is a membrane stabilizing agent (Terakawa, 1985) and blocks most ionic channels. After 15 min perfusion of cultured chromaffin cells with NS containing $3.5 \mathrm{~mm}$ lidocaine, the number of filopodia induced by electrical stimulation in a single terminal greatly decreased from the control value of
$5.09 \pm 1.06$ to $0.27 \pm 0.19(n=23, p<0.01)$. The filopodial formation induced by application of a solution containing 65 $\mathrm{mm} \mathrm{KCl}$ was totally abolished in the presence of $3.5 \mathrm{~mm}$ lidocaine $(n=9, p<0.01)$.

\section{Relationship between filopodial formation and exocytosis}

To study the filopodial formation in detail, we analyzed dynamic features of sprouting process further in nerve terminals of chromaffin cells by tracing the tip of filopodia. A result of such an analysis is shown in Figure 8. As mentioned earlier, the filopodia sprouted rapidly were very flexible and were moving constantly. The movements of the tips of these filopodia were traced manually using a cursor on the video monitor. The position of the cursor was continuously registered into the computer. In this two-dimensional projection, the tips of the filopodia moved randomly, but they mostly stayed outside of the terminal edge and rarely crossed the source point towards the terminal (Fig. $8 A$ ), suggesting that an outward ejecting force is operating in their rapid sprouting. The exact length of the filopodia was very 


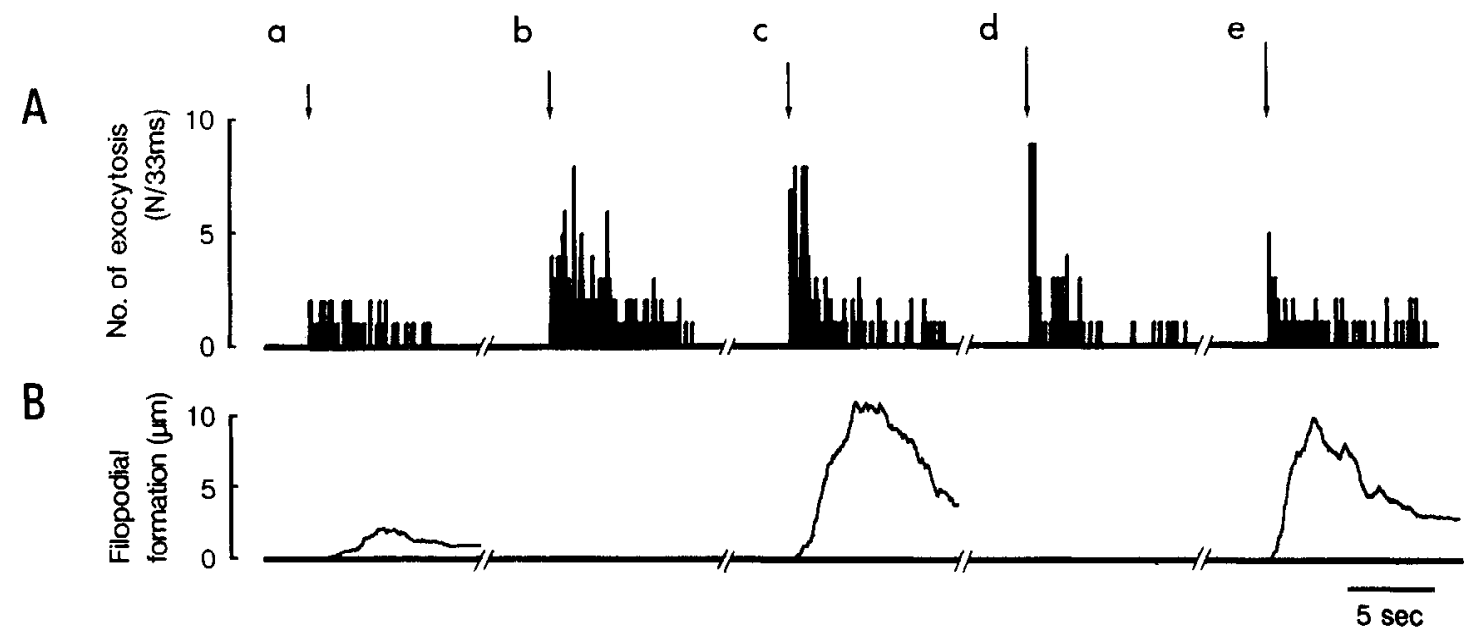

Figure 9. Comparison of exocytosis and filopodial formation in a single terminal of a chromaffin cell. $A$, Individual exocytotic events in response to electrical stimulation were counted in every video frame $(33 \mathrm{msec}$ interval). $B$, Extent of filopodial sprouting observed simultaneously in the same terminal. Traces were drawn as explained for Figure 8. Each stimulus was given at an interval of about 1 min (except traces $c$ and $d$, where the interval was about $2 \mathrm{~min}$ ). The terminal was stimulated with an electrical pulse of $1 \mathrm{msec}$ duration at the time indicated by arrows. The length of arrows refers approximately to the relative intensity of electrical stimulation. Note absence of consistent correlation between the two events.

difficult to measure when they moved three-dimensionally. Therefore, we used the linear distance between the tip of the filopodia and the source point of the same filopodia in a twodimensionally projected image as an indication of filopodial length (Fig. 8B). A separate trace was drawn for each of the filopodium in a single terminal. Such traces showed that the time when all the filopodia began to form was almost the same. The time when all the filopodia retracted and went back to the source point was also about the same even though the filopodia arose from source points far away from each other. This suggests that there may be a common internal signal that mediates their formation and retraction. The rate of elongation could also be measured from such traces. It was rapid though not equal in all the filopodia, with the highest rate being $1.7-2.0 \mu \mathrm{m} / \mathrm{sec}$. The sum of the linear length of all filopodia produced in a single terminal can be used to approximately quantify the extent of filopodial formation in that terminal (Fig. $8 B$, bottom).

To test the hypothesis that cell processes may be formed when secretory granule membrane is incorporated into plasma membrane by the exocytotic fusion process (Clark et al., 1972; Burwen and Satir, 1977; Englert, 1980), we examined a correlation between the exocytotic events and filopodial sprouting induced by the same stimulus in a single terminal of chromaffin cells. As mentioned earlier, exocytosis was seen as abrupt changes in appearance of the chromaffin granules in response to chemical and depolarizing stimulation (Terakawa et al., 1991, 1992, $1993 a, b)$. The frequency of such responses of the granules in the terminal were counted on a time differentiated video record (Terakawa et al., 1991). The extent of filopodial formation in the same terminal was quantified by the procedure explained above. Thus, we could quantitatively compare the filopodial formation with the exocytotic activity in a single terminal (Fig. 9). There was no consistent correlation between the two cvents. In some cases, exocytosis and filopodial sprouting were induced simultaneously with a single stimulus, and they could not be separated by changing the stimulus intensity. However, in many cases, the intensities of electrical stimulation required to produce these two responses were different, being slightly higher for filopodial sprouting than exocytosis. Frequently, only exo- cytosis appeared, and no filopodium was formed at all, irrespective of a damagingly strong stimulation. Some terminals showed frequent exocytotic responses in a localized region, but sprouted many filopodia in other regions. Filopodia elongated while exocytotic responses completely stopped, or filopodia started withdrawing while many exocytotic responses still continued. When exocytotic responses were very frequent, large caveolar invaginations were formed as a result of multiple fusion of the $\Omega$-figures. These invaginations maintained their form for a rather long time ( $\sim-10 \mathrm{~min})$. In a few cases, electrical stimulation induced only filopodial sprouting and no exocytosis. These terminals failed to show exocytosis even upon the strongest stimulation. This was the case in most terminals in PC12 cells, in which the frequency of the exocytotic response was extremely low, whereas the terminals that showed filopodial sprouting abounded. These results suggest that filopodial sprouting and exocytosis are two independent events not directly related to each other.

Filopodial sprouting was localized to the varicosities and terminals of neurites. No filopodium was formed from the thin part of the neurite (axonal region) or from the round cell body of differentiated and undifferentiated chromaffin cells despite their direct and strong electrical stimulation. The same was true for the differentiated PC12 cells. This is in some contrast to previous observations (Cornell-Bell et al., 1990). In more than a hundred chromaffin cells, we have observed a high activity of exocytosis but no filopodial sprouting in the region of cell body. This again suggests that both activities are probably independent and not linked as a cause and result.

\section{Discussion}

We described a rapid morphological change occurring in nerve tcrminals of differentiated chromaffin cells and PC1 2 cells upon electrical stimulation. Our results indicate that nerve terminals are capable of forming filopodia very rapidly in a calcium dependent manner in response to a brief membrane depolarization. This filopodial sprouting activity was facilitated by repetitive stimulation. The activity was not directly related to exocytosis of transmitter-containing granules, but correlated with 
the state of differentiation or growth of the neuronal cells. We speculate that this morphological change might be involved in regulated growth of the nerve terminal, use-dependent synapse formation, or tetanus-induced synaptic plasticity.

\section{Dependence on $\mathrm{Ca}^{2+}$}

The intracellular $\mathrm{Ca}^{2+}$ level is higher in the growth cone when compared with the soma or the proximal part of neurites of growing neurons (Connor, 1986). Treatment with strong or high concentration of Ca-channel blockers inhibits the motility of the growth cone and the neurite elongation (Mattson and Kater, 1987). Rapid filopodial sprouting as described in Results requires the presence of $\mathrm{Ca}^{2+}$ in the extracellular medium and can be abolished completely by lanthanum, a $\mathrm{Ca}^{2+}$ influx inhibitor. Therefore, this response is induced by a rise in intracellular $\mathrm{Ca}^{2+}$ level above that present at the nerve terminal. Rapid sprouting of filopodia occurred in the presence of some specific Ca-channel blockers, suggesting that opening of a few classes of voltagedependent $\mathrm{Ca}^{2+}$ channels and resulting $\mathrm{Ca}^{2+}$ influx are sufficient to induce the filopodial sprouting.

The higher threshold of stimulation for filopodial sprouting than for exocytosis can be explained by assuming a graded (not all-or-none) type of voltage dependence of terminal Ca channels and a strong Ca requirement for the former response. It is likely that filopodial sprouting is an immediate consequence of a rise in intracellular $\mathrm{Ca}^{2+}$ concentration to a rather high level. This $\mathrm{Ca}$ requirement for the rapid filopodial sprouting is similar to that for filopodial elongation in Helisoma growth cones (Davenport and Kater, 1992; Rehder and Kater, 1992). On the contrary, it has been shown that a sustained increase in intracellular $\mathrm{Ca}^{2+}$ concentration to very high levels by repeated electrical stimulation (Cohan and Kater, 1986), or by continuous application of neurotransmitters (Haydon et al., 1984) suppressed both growth cone motility and elongation. This led to the suggestion that there are optimum levels of intracellular $\mathrm{Ca}^{2+}$ for promoting the growth cone motility and elongation and that these responses may have different sensitivities to calcium (Mattson and Kater, 1987). It is possible that the responses we described are also induced by a rise in intracellular $\mathrm{Ca}^{2+}$ concentration to the same optimal level. Failure to maintain the $\mathrm{Ca}^{2+}$ level within the optimal range could be one of the reasons why these filopodia did not persist and retracted rapidly.

\section{Mechanism of filopodial formation}

Various mechanisms have been suggested to explain process formation in different cells. The surface of unfertilized sea urchin eggs is covered with numerous microvilli that abruptly elongate after fertilization (Schroeder, 1978). Increase in intracellular $\mathrm{Ca}^{2+}$ level (Steinhardt et al., 1977) or pH level (Mazia et al., 1975) following fertilization is believed to induce actin polymerization necessary for cytoskeletal extension in the process (Schroeder, 1978; Begg and Rebhun, 1979). The sperm acrosome also elongates very rapidly ( $>50 \mu \mathrm{m} / \mathrm{sec}$ ), and this elongation is mediated by polymerization of highly organized microfilaments (Tilney et al., 1978; Tilney and Inoue, 1982). It is known that the common (stable) filopodia on growth cone grow slowly by treadmilling of actin filaments and are stabilized by a bundle of such filaments (Wang, 1985; Smith, 1988). Filopodia induced by glutamate stimulation in astrocytes contain dense actin filaments (Cornell-Bell et al., 1990). Therefore, filopodia in the present preparation may be elongated by a sliding or treadmilling of actin filaments similarly to egg microvilli and sperm acrosome.
However, the thinness and flexibility of these filopodia reflect a sparsity of cytoskeleton, if any at all, and the effect of cytochalasin B on filopodial sprouting was not strong enough to support this view. The rapidly formed filopodia probably have a mechanism of formation different from that of much larger filopodia described by Wang (1985). We attempted to fix filopodia with glutaraldehyde to confirm the presence of microfilaments in filopodia by electron microscopy, but failed because of their transient nature. This again suggests a sparsity of proteinaceous components in the rapidly formed filopodia.

An alternative to the cytoskeletal mechanism is a deformation of the cell membrane per se by an osmotic effect. Liposomes made artificially using phospholipids can be deformed to various tubular shapes by a small osmotic change in the medium (Hotani, 1984). Sometimes, spherical liposomes sprout thin tubes of $0.5 \mu \mathrm{m}$ in diameter. A similar effect may be induced in nerve terminals by a local increase in intracellular $\mathrm{Ca}^{2+}$ concentration and by opening of ionic channels. Membrane-associated cytoskeleton may be degraded locally to increase membrane deformability in a Ca-dependent manner. The osmotic pressure may cxcrts its cffcct on this weak point of the membrane. The suppressive effect of lidocaine on the filopodial sprouting is well interpreted by assuming that lidocaine stabilizes the structure of phospholipid membrane in addition to blocking ionic channels. In fact, surface active agents are also known to stabilize membranes against hypotonic and mechanical stresses (Seeman and Weinstein, 1966). Further analyses are necessary to determine which of the above two possibilities is involved in the rapid filopodial sprouting.

Formation of cellular processes was imagined to be a consequence of the incorporation of secretory membrane into the plasma membrane by exocytosis (Clark et al., 1972; Taylor et al., 1973; Burwen and Satir, 1977; Englert, 1980). A similar process was thought to occur during extension of the growth cone as well (Bray, 1973). Although no experimental evidence for this view has been obtained to date, this is still a possible mechanism for rapid filopodial sprouting. Differentiated chromaffin cells provided a rare opportunity to clarify this point, because exocytotic responses of small granules were directly visible in the growth cone. Our observations indicated that rapid filopodial sprouting and exocytosis were not quantitatively related and did not always occur together. A lack of a close correlation between both events was obvious. A surplus membrane incorporated into the plasma membrane by exocytosis remained as a caveolar invagination but never as a protrusion. In PC12 cells, filopodia elongated rather frequently despite an extremely rare occurrence of exocytotic responses. Therefore, it is difficult for secretory vesicle membrane to account for the increase in filopodial membrane. The filopodial membrane may be supplied by stretching and unfolding of the terminal membrane or by invisible incorporation of membrane molecules by an unknown mechanism.

\section{Physiological significance}

Various functions have been ascribed to activities of filopodia that are normally present in the growth cone. Some suggested a direct role in growth cone extension (Bray and Chapman, 1985; Heidemann et al., 1990). Others suggested that filopodia may act as structural supports (Yamada et al., 1971; Goldberg and Burmeister, 1986). Studies with anticytoskeletal agents showed that filopodia may play a more important role in growth cone steering (Marsh and Letourneau, 1984; Bentley and Torian- 
Raymond, 1986). Filopodia explore the territory around the growth cone and locate suitable target cells (Bentley and Keshishian, 1982; Bastiani et al., 1984; O'Connor et al., 1990). The time course of these events is much slower than filopodial sprouting induced by electrical stimulation, but this does not eliminate the possibility that the same may be the role played by rapidly formed filopodia as well. Their transient nature could be simply due to the absence of a suitable target in the vicinity. Each functions of the growth cone, steering the neurites, selecting the proper target cells, forming synaptic connections, and making synaptic rearrangements, are performed at a suitable time of development and are promoted or suppressed according to age or state of differentiation (Winick and Greenberg, 1965; Herrup and Shooter, 1975; Agiro et al., 1984). The rate of neurite extension, in fact, varies in vitro (Ebendal, 1979; McLennan and Hendry, 1980; Collins and Lee, 1982; Agiro et al., 1984) and in vivo (Black and Lasek, 1979; Schreyer and Jones, 1982). Growth cone morphology also varies with the state of differentiation and rate of neurite extension (Agiro et al., 1984). We observed that the filopodial sprouting activity was maintained at the highest level in a period when PC1 2 cells extended their neurites rapidly (Fig. 5). It is possible, therefore, that the filopodial sprouting activity might have a functional role in neurite extension or synapse formation.

Signal transmission in the synapse is potentiated when it is stimulated tetanically (Bliss and Lomo, 1973). A Ca-activated protease (Lynch and Baudry, 1984) and a growth associated protein, GAP-43 (Akers and Routtenberg, 1987), are considered to be involved in this potentiation. The protease may degrade membrane associated cytoskeletons and thus increase membrane deformability. GAP-43 transfected into non-neuronal cells is known to induce filopodia (Zuber et al., 1989). We showed that the repetitive stimulation is favorable for filopodial sprouting. Taking them together, we speculate that, when stimulated tetanically, the presynaptic terminal sprouts filopodia rapidly in vivo in support of the synaptic potentiation.

\section{References}

Agiro V, Bunge MB, Johnson MI (1984) Correlation between growth form and movement and their dependence on neuronal age. J Neurosci 4:3051-3062.

Akers RF, Routtenberg A (1987) Calcium-promoted translocation of protein kinase $\mathrm{C}$ to synaptic membranes: relation to the phosphorylation of an endogenous substrate (protein F1) involved in synaptic plasticity. J Neurosci 7:3976-3983.

Archer SM, Dubin MW, Stark LA (1982) Abnormal development of kitten retino-geniculate connectivity in the absence of action potentials. Science 217:743-745.

Bastiani MJ, Raper JA, Goodman CS (1984) Pathfinding by neuronal growth cones in grasshopper embryos. $J$ Neurosci 4:2311-2328.

Begg DA, Rebhun LI (1979) $\mathrm{pH}$ regulates the polymerization of actin in the sea urchin egg cortex. J Cell Biol 83:241-248.

Bentley D, Keshishian H (1982) Pathfinding by peripheral pioneer neurons in grasshoppers. Science 218:1082-1088.

Bentley D, Torian-Raymond A (1986) Disoriented pathfinding by pioneer neurone growth cones deprived of filopodia by cytochalasin treatment. Nature 323:712-715.

Black MM, Lasek RJ (1979) Slowing of the rate of axonal regeneration during growth and maturation. Exp Neurol 63:108-119.

Bliss TVP, Lomo T (1973) Long lasting potentiation of synaptic transmission in the dentate area of the anesthetized rabbit following stimulation of the perforant path. J Physiol (Lond) 232:331-356.

Borgens RB, Roederer E, Cohen MJ (1981) Enhanced spinal cord regeneration in lamprey by applied electric fields. Science 213:611617.

Bray D (1973) Model for membrane movements in the neural growth cone. Nature 244:93-96.
Bray D, Chapman K (1985) Analysis of microspike movements on the neuronal growth cone. J Neurosci 5:3204-3213.

Brown MC, Ironton R (1977) Motor neurone sprouting induced by prolonged tetrodotoxin block of nerve action potentials. Nature 265: 459-461.

Brown MC, Holland RL, Hopkins WG (1981) Motor nerve sprouting. Annu Rev Neurosci 4:17-42.

Burwen SJ, Satir BH (1977) Plasma membrane folds on the mast cell surface and their relationship to secretory activity. J Cell Biol 74: 690-697.

Changeux JP, Danchin A (1976) Selective stabilisation of developing synapses as a mechanism for the spccification of ncuronal networks. Nature 264:705-712.

Clark AW, Hurlbut WP, Mauro A (1972) Changes in the fine structure of the neuromuscular junction of the frog caused by black widow spider venom. J Cell Biol 52:1-14.

Cohan CS, Kater SB (1986) Suppression of neurite elongation and growth cone motility by electrical activity. Science 232:1638-1640.

Collins F, Lee MR (1982) A reversible developmental change in the ability of ciliary ganglion neurons to extend neurites in culture. $J$ Neurosci 2:424-430.

Connolly JL, Seeley PJ, Greene LA (1987) Rapid regulation of neuronal growth cone shape and surface morphology by nerve growth factor. Neurochem Res 12:861-868.

Connor JA (1986) Digital imaging of free calcium changes and of spatial gradients in growing processcs in single, mammalian central nervous system cells. Proc Natl Acad Sci USA 83:6179-6183.

Cornell-Bell AH, Thomas PG, Smith SJ (1990) The excitatory neurotransmitter glutamate causes filopodia formation in cultured hippocampal astrocytes. Glia 3:322-334.

Davenport RW, Kater SB (1992) Local increases in intracellular calcium elicit local filopodial responses in Helisoma neuronal growth cones. Neuron 9:405-416.

Ebendal T (1979) Stage-dependent stimulation of neurite outgrowth exerted by nerve growth factor and chick heart in cultured embryonic ganglia. Dev Biol 72:276-290.

Englert DF (1980) An optical study of isolated rat adrenal chromaffin cells. Exp Cell Res 125:369-376.

Forscher P, Smith SJ (1988) Actions of cytochalasins on the organization of actin filaments and microtubules in a neuronal growth cone. J Cell Biol 107:1505-1516.

Goldberg DJ, Burmeister DW (1986) Stages in axon formation: observations of growth of Aplysia axons in culture using video-enhanced contrast-differential interference contrast microscopy. J Cell Biol 103: 1921-1931.

Hatanaka H (1981) Nerve growth factor-mediated stimulation of tyrosine hydroxylase activity in a clonal rat pheochromocytoma cell line. Brain Res 222:225-233.

Haydon PG, McCobb DP, Kater SB (1984) Serotonin selectively inhibits growth cone motility and synaptogenesis of specific identified neurons. Science 226:561-564.

Heidemann SR, Lamoureux P, Buxbaum RE (1990) Growth cone behavior and production of traction force. J Cell Biol 111:1949-1957.

Herrup K, Shooter EM (1975) Properties of the beta-nerve growth factor receptor in development. J Cell Biol 67:118-125.

Hotani H (1984) Transformation pathways of liposomes. J Mol Biol 178:113-120.

Ip NY, Zigmond RE (1984) Pattern of presynaptic nerve activity can determine the type of neurotransmitter regulating a postsynaptic event. Nature 31 1:472-474.

Lomo T, Rosenthal J (1972) Control of ACh sensitivity by muscle activity in the rat. J Physiol (Lond) 221:493-513.

Lynch G, Baudry M (1984) The biochemistry of memory: a new and specific hypothesis. Science 224:1057-1063.

Manivannan S, Terakawa S (1993) Rapid filopodial sprouting induced by electrical stimulation in nerve terminals. Jpn J Physiol 43[Suppl 1]:S217-S220.

Marsh L, Letourneau PC (1984) Growth of neurites without filopodial or lamellipodial activity in the presence of cytochalasin B. J Cell Biol 99:2041-2047.

Mattson MP, KaterSB (1987) Calcium regulation of neurite elongation and growth cone motility. J Neurosci 7:4034-4043.

Mazia D, Schatten G, Steinhardt R (1975) Turning on of activities in unfertilized sea urchin eggs: correlation with changes of the surface. Proc Natl Acad Sci USA 72:4469-4473. 
McLennan IS, Hendry IA (1980) Influence of cardiac extracts on cultured ciliary ganglia. Dev Neurosci 3:1-10.

O'Connor TP, Duerr JS, Bentley D (1990) Pioneer growth cone steering decisions mediated by single filopodial contacts in situ. J Neurosci 10:3935-3946.

Patel NB, Poo MM (1982) Orientation of neurite growth by extra cellular electric fields. J Neurosci 2:483-496.

Rehder V, Kater SB (1992) Regulation of neuronal growth cone filopodia by intracellular calcium. J Neurosci 12:3175-3186.

Schreyer DJ, Jones EG (1982) Growth and target finding by axons of the corticospinal tract in prenatal and postnatal rats. Neuroscience 7:1837-1853.

Schroeder TE (1978) Microvilli on sea urchin eggs: a second burst of elongation. Dev Biol 64:342-346.

Seeman P, Weinstein J (1966) Erythrocyte membrane stabilization by tranquilizers and antihistamines. Biochem Pharmacol 15:1737-1752.

Smith SJ (1988) Neuronal cytomechanics: the actin-based motility of growth cones. Science 242:708-715.

Steinhardt R, Zucker R, Schatten G (1977) Intracellular calcium release at fertilization in the sea urchin egg. Dev Biol 58:185-196.

Taylor DL, Condeelis JS, Moore PL, Allen RD (1973) The contractile basis of amoeboid movement. I. The chemical control of motility in isolated cytoplasm. J Cell Biol 59:378-394.

Terakawa S (1985) Potential dependent variations of the intracellular pressure in the intracellularly perfused squid giant axon. J Physiol (Lond) 369:229-248.

Terakawa S, Fan JH, Kumakura K, Imaizumi MO (1991) Quantitative analysis of exocytosis directly visualized in living chromaffin cells. Neurosci Lett 123:82-86.

Terakawa S, Manivannan S, Kumakura K (1992) Exocytosis in nerve terminals of the cultured bovine chromaffin cell studied at a single granule level. J Physiol (Lond) 446:205P.

Terakawa S, Manivannan S, Kumakura K (1993a) Exocytosis in the growth cone of differentiated chromaffin cells induced by electrical stimulation. Jpn J Physiol 43[Suppl 1]:S213-S216.
Terakawa S, Manivannan S, Kumakura K (1993b) Evidence against the swelling hypothesis for initiation of exocytosis in terminals of chromaffin cell processes. J Physiol (Paris) 87:209-213.

Tilney LG, Inoue S (1982) Acrosomal reaction of the thyone sperm. II. The kinetics and possible mechanism of acrosomal process elongation. J Cell Biol 93:820-827.

Tilney LG, Kiehart DP, Sardet C, Tilney M (1978) Polymerization of actin. IV. Role of $\mathrm{Ca}^{++}$and $\mathrm{H}^{+}$in the assembly of actin and in membrane fusion in the acrosomal reaction of echinoderm sperm. $\mathbf{J}$ Cell Biol 77:536-550.

Walicke PA, Campenot RB, Patterson PH (1977) Determination of transmitter function by neuronal activity. Proc Natl Acad Sci USA 74:5767-5771.

Wang YL (1985) Exchange of actin subunits at the leading edge of living fibroblasts: possible role of treadmilling. J Cell Biol 101:597602.

Waymire JC, Bennet F, Boehme R, Hankins L, Waymire KG, Haycock JW (1983) Bovine adrenal chromaffin cells: high-yield purification and viability in suspension culture. J Neurosci Methods 7:329-351.

Winick M, Greenberg RE (1965) Chemical control of sensory ganglia during a critical period of development. Nature 205:180-181.

Yamada KM, Spooner BS, Wessells NK (1971) Ultrastructure and function of growth cones and axons of cultured nerve cells. J Cell Biol 49:614-635.

Yamaguchi K (1990) Enhancement of the $\mathrm{Ca}^{2+}$-current by a serum factor in cultured dorsal root ganglia neurons of the adult guinea pig. Brain Res 529:286-293.

Zigmond REE, Bowers CW (1981) Influence of nerve activity on the macromolecular content of neurons and their effector organs. Annu Rev Physiol 43:673-687.

Zuber MX, Goodman DW, Karns LR, Fishman MC (1989) The neuronal growth-associated protein GAP-43 induces filopodia in nonneuronal cells. Science 224:1193-1195. 